\title{
A HERMENÊUTICA JURÍDICA COMO CAMINHO PARA O REEQUILÍBRIO \\ DA PROTEÇÃO DO DIREITO À INFORMAÇÃO NAS RELAÇÕES DE CONSUMO NA SOCIEDADE DA INFORMAÇÃO.
}

\section{Roberto Senise Lisboa*}

\author{
João Felipe Oliveira Brito**
}

Resumo: A Sociedade da Informação traz consigo debates importantes especialmente no que diz respeito à interpretação do direito frente as relações jurídicas decorrentes das novas tecnologias, novas formas de comunicação, interação, comercialização etc. O presente artigo investiga a mitigação do direito à informação e o dever de informar na atualizada, e apresenta a revisitação da hermenêutica jurídica como caminho para o reequilíbrio da proteção do direito à informação nas relações de consumo na sociedade da informação. A pesquisa serviu-se da técnica baseada em fonte documental, bibliográfica, legislativa, e judicial e pesquisa empírica indireta.

Palavras-chave: sociedade da informação; direito do consumidor; relação de consumo; direito à informação; hermenêutica jurídica

Abstract: The Information Society brings with it important debates, especially with regard to the interpretation of law in relation to the legal relations arising from new technologies, new forms of communication, interaction, commercialization, etc. This article investigates the mitigation of the right to information and the duty to inform in the updated one, and presents the revision of legal hermeneutics as a way to rebalance the protection of the right to information in consumer relations in the information society. The research used the technique based on documentary, bibliographic, legislative, and judicial source and indirect empirical research.

Keywords: information societyconsumer lawconsumer relationshipright to informationlegal hermeneutics

\footnotetext{
* Livre-Docente e Doutor em Direito Civil pela USP - Universidade de São Paulo. Coordenador do Programa de Mestrado Acadêmico em Direito, área de concentração Direito da Sociedade da Informação, no Centro Universitário das Faculdades Metropolitanas Unidas - FMU. Professor do Programa de Mestrado Acadêmico em Direito, área de concentração Direito da Sociedade da Informação, no Centro Universitário das Faculdades Metropolitanas Unidas - FMU. Professor Emérito de Direito Civil do Curso de Graduação no Centro Universitário das Faculdades Metropolitanas Unidas - FMU. Professor de Direito Internacional do Curso de Graduação na Pontifícia Universidade Católica de São Paulo - PUCSP. Endereço Postal: Avenida da Liberdade, $\mathrm{n}^{\circ} 749$ Liberdade, São Paulo/SP, CEP 01503-001. E-mail: roberto.senise@fmu.br

** Mestrando em Direito da Sociedade da Informação no Centro Universitário das Faculdades Metropolitanas Unidas (FMU). Docente no curso de Direito da Universidade Brasil - Diadema. Endereço Postal: Rua Caruso, $\mathrm{n}^{\circ}$ 115, Vila Alpina, São Paulo/SP, CEP 03211-060. E-mail:oliveirabritoadv@gmail.com
} 


\section{INTRODUÇÃO}

As transformações advindas da evolução tecnológica nas últimas décadas refletem-se em todos os segmentos da sociedade de forma jamais observada. A globalização decorrente da evolução tecnológica traz benefícios à sociedade como um todo, possibilitando o desenvolvimento e a circulação de ideias, informações e conhecimento em larga escala e de forma praticamente instantânea, rompendo as barreiras físicas e geográficas.

Seguindo esse contexto revolucionário, a Sociedade da Informação nasce e se desenvolve, modificando as relações já existentes e criando novas relações sociais e jurídicas, fomentando debates e questionamentos, especialmente no que diz respeito à interpretação do direito frente as relações jurídicas decorrentes das novas tecnologias, novas formas de comunicação, interação, comercialização, etc.

O Estado (brasileiro, no caso), especialmente por intermédio do Poder Judiciário, diante da evolução tecnológica pela qual a sociedade global tem passado ao longo das últimas décadas, vê-se obrigado a lidar e dirimir novos conflitos decorrentes dessa sociedade informacional, sem a proporcional evolução normativa e, por vezes, interpretativa dos próprios julgadores

Dadas modificações nas relações sociais, econômicas, culturais, políticas e jurídicas provocadas pela revolução tecnológica, é certo que o atual panorama normativo e de produção normativa no sistema jurídico brasileiro, bem como o padrão de hermenêutica jurídica dominante são insuficientes "para fazer frente às mudanças sociais causadas pelo rápido avanço tecnológico" (PAESANI, 2007, p. 02), gerando conflitos e questionamentos acerca de como o direito deve ser interpretado e aplicado aos casos concretos.

Em que pese a existência de variadas correntes de pensamento a respeito da interpretação do direito, na Idade Contemporânea a concepção dominante sobre o direito e a hermenêutica jurídica, notadamente no Brasil, é indiscutivelmente positivista. A maioria dos operadores do direito - em razão das estruturas institucionais do Estado e do direito contemporâneo, pela formação teórica e/ou pela prática jurídica -, considera que o direito é constituído por um conjunto sistemático de normas positivadas pelo Estado, restringindo a sua atividade à mera interpretação e reprodução do texto normativo positivado, deixando de lado as circunstâncias externas a ele. Tal concepção sobre a atividade hermenêutica, em razão da 
limitação normativista, não dá conta de abranger a pluralidade e a evolução da sociedade, especialmente no que diz respeito à sociedade da informação, tendo em vista que a produção normativa não consegue acompanhar, no mesmo ritmo, a evolução tecnológica. Esse tipo de corrente de pensamento pode ser acusada, inclusive, como responsável por limitar a evolução do direito e da sociedade.

Considerando-se as diversas circunstâncias que circundam a Sociedade da Informação e os reflexos que ela gera na sociedade, é imperativo que os ramos, a teoria e a filosofia do direito sejam revisitados, de modo a atualizar e adaptar do direito e a hermenêutica jurídica à era informacional na qual vivemos.

Trata-se de pesquisa de caráter exploratório e de revisão conceitual e interpretativa, que investigará, pela técnica de bibliográfica, por meio de artigos científicos, livros, normas constitucionais e infraconstitucionais e decisão judicial, os principais conceitos sobre o tema para se atingir o objetivo almejado.

\section{1 - A SOCIEDADE DA INFORMAÇÃO}

De acordo com Roberto Senise Lisboa, a sociedade da informação, que também pode ser denominada de "sociedade do conhecimento", identifica o período histórico a partir do qual há a “[...] preponderância da informação sobre os meios de produção e a distribuição dos bens na sociedade que se estabeleceu a partir da vulgarização das programações de dados utiliza dos meios de comunicação existentes [...]” (SENISE LISBOA, 2006, p. 87), não se limitando, “[...] pois, ao computador ou a um direito informático (vide tópico seguinte), já que estende-se a qualquer meio de comunicação presencial ou não" (SENISE LISBOA, 2006, p. 87).

"Desde as formas de conhecimento e de obtenção de informações e dados rudimentares até as mais sofisticas por força do implemento da tecnologia, percebe-se a valorização que se dá, especialmente nesse início de século, à informação" (SENISE LISBOA, 2006, p. 89).

Liliana Minardi Paesani (2009, p. 41) considerava que “[...] a principal transformação recente nas sociedades contemporâneas envolve uma verdadeira revolução digital em que são dissolvidas as fronteiras entre telecomunicações, meios de comunicação de massa e informática [...]” denominando esse ciclo, assim como Roberto Senise Lisboa, de Sociedade da Informação, cuja principal característica, ainda segundo ela, “[...]é o surgimento de complexas redes profissionais e tecnológicas voltadas à produção e ao uso da informação, que alcançam ainda 
sua distribuição através do mercado, bem como as formas de utilização desse bem para gerar conhecimento e riqueza" [...].

O advento da internet, atualmente, pode ser considerado como uma das molas propulsoras da revolução tecnológica, digital e informacional vivida pela sociedade global, considerando-se, especialmente, os eventos, descobertas e invenções observadas nas últimas décadas. Isso porque a internet é o meio de comunicação que permitiu, em escala global, a comunicação de muitos com muitos, a tomada de decisões coordenadas e com execução descentralizada, a flexibilidade no desempenho de tarefas, possibilitando uma "[...] forma organizacional superior para a ação humana [...] (CASTELLS, 2003, p. 8). "Atividades econômicas, sociais, políticas, e culturais essenciais por todo o planeta estão sendo estruturadas pela Internet e em torno dela [...]" (CASTELLS, 2003, p. 8), modificando relações jurídicas, comerciais, pessoais, estatais, internacionais, entre outras.

A Sociedade da Informação traz consigo relevantes benefícios à sociedade como um todo, possibilitando o desenvolvimento e a circulação de ideias, informações e conhecimento em larga escala e de forma praticamente instantânea, rompendo as barreiras físicas e geográficas. “A massificação da informação estabeleceu-se como a mola propulsora da economia e gerou transformações sociais igualmente profundas, cujas extensões últimas ainda não foram alcançadas, nem de fato cogitadas" (SENISE LISBOA, 2009, p. 9).

Por outro lado, traz consigo, também, debates, questionamentos e problemáticas importantes em diversos seguimentos da sociedade, dentre eles, o econômico, o social, o político e o jurídico, considerando-se, dentre outros, o domínio das tecnologias da informação e de acesso à informação por empresas privadas e/ou governos; a exclusão digital e, consequentemente, social daqueles que não têm acesso ou, quando o têm, o acesso é limitado; e as consequências econômicas, sociais e políticas decorrentes deste fenômeno, que devem ser objeto de preocupação e estudo nas mais diversas áreas do conhecimento, de modo que a evolução tecnológica e informacional sirva ao benefício da sociedade global como um todo, e não de pequenos grupos hegemônicos já detentores de poder social, econômico e político.

\section{2 - A PROTEÇÃO JURÍDICA DO CONSUMIDOR E O DIREITO À INFORMAÇÃO}




\section{A HERMENÊUTICA JURÍDICA COMO CAMINHO PARA O REEQUILÍBRIO \\ DA PROTEÇÃO DO DIREITO À INFORMAÇÃO NAS RELAÇÕES \\ DE CONSUMO NA SOCIEDADE DA INFORMAÇÃO.}

\section{1 - A PROTEÇÃO JURÍDICA DO CONSUMIDOR COMO DIREITO FUNDAMENTAL}

O consumo é inerente à vida humana, já que, para garantir a sobrevivência, é indispensável o consumo de recursos naturais e industrializados diariamente. Todo indivíduo torna-se consumidor (direto ou por equiparação) em algum momento da vida. Em vista da importância do consumo para a sociedade e o Estado, a Constituição Federal de 1988 reconheceu o consumidor como sujeito de direitos, assegurando a sua proteção constitucional por meio do reconhecimento como direito fundamental (artigo $5^{\circ}$, inciso XXXII, da CF) e como princípio de ordem econômica (art. 170, inciso V, da CF), além de ser a origem da codificação tutelar dos direitos consumeristas, haja vista que o artigo 48 do Ato das Disposições Constitucionais Transitórias estabeleceu que o legislador criasse um Código de Defesa e Proteção do Consumidor.

Cláudia Lima Marques (MARQUES, BENJAMIM, BESSA, 2014, p. 77), referindose à origem constitucional das normas de defesa do consumidor, expõe o seguinte:

\footnotetext{
Em resumo, certos estão aqueles que consideram a Constituição Federal de 1988 como o centro irradiador e o marco de reconstrução de um direito privado brasileiro mais social e preocupado com os vulneráveis de nossa sociedade, um direito privado solidário. Assim, temos hoje uma força interpretativa da menção constitucional ao consumidor, isto é, o direito privado não pode ser interpretado "contra" o - e sim, sempre a favor do - sujeito de direito identificado pela Constituição como sujeito vulnerável a ser protegido pelo Poder Judiciário e Executivo e uma "força normativa" imposta a estes poderes como guia de atuação positiva e funcional, que também vincula o Poder Legislativo. Em outras palavras, a Constituição seria a garantia (de existência e de proibição de retrocesso) e o limite (limite-guia e limite-função) de um direito privado construído sob seu sistema de valores e incluindo a defesa do consumidor como princípio geral.
}

Dando efetividade aos mandamentos constitucionais, o legislador editou a Lei 8.078/90, estabelecendo as normas de proteção e defesa do consumidor, de ordem pública e interesse social. "Em outras palavras, a proteção do consumidor como direito fundamental constitucional e não apenas como direito básico inserido na Lei $n^{\circ} 8.078$, de 11.9.1990" (SENISE LISBOA, 2009, p. 20). 


\section{2 - O DIREITO À INFORMAÇÃO E O DEVER DE INFORMAR NO CÓDIGO DE DEFESA DO CONSUMIDOR E A IMPORTÂNCIA NAS RELAÇÕES DE CONSUMO}

O Código de Defesa do Consumidor instituiu, no artigo 4a, a Política Nacional de Relações de Consumo, estabelecendo os objetivos e as diretrizes principiológicas para atendimento das necessidades dos consumidores. Dentre os princípios elencados pelo referido dispositivo legal, observa-se o inciso IV, que estabelece a "educação e informação de fornecedores e consumidores, quanto aos seus direitos e deveres", como princípio a ser observado nas relações de consumo, "com vistas à melhoria do mercado de consumo".

Marques considera que "[...] direito à informação, garantia fundamental da pessoa humana expressa no art. 5. ${ }^{\circ}, \mathrm{XIV}$ da $\mathrm{CF} / 1988$, é gênero do qual é espécie também previsto no Código de Defesa do Consumidor" (MARQUES, BENJAMIM, BESSA, 2014, p. 78).

Além de estar disposto como princípio, o direito à informação é apresentado como direito básico do consumidor no inciso III, do artigo $6^{\circ}$ do Código de Defesa do Consumidor, que estabelece ser de direito do consumidor o recebimento de "informação adequada e clara sobre os diferentes produtos e serviços, com especificação correta de quantidade, características, composição, qualidade, tributos incidentes e preço, bem como sobre os riscos que apresentem".

O dever de informar, decorrente do princípio e do direito básico do consumidor à informação, está disposto, dentre outros, mas especialmente, nos artigos 31 , 46 e 54, $\S \S 3^{\circ}$ e $4^{\circ}$, todos do Código de Defesa do Consumidor, que tratam, respectivamente, do dever de informar na oferta e apresentação de produtos; sobre a não vinculação do consumidor quando não lhe for dada a oportunidade de tomar conhecimento prévio do conteúdo do contrato ou quando o instrumento for redigido de modo a dificultar a compreensão do seu sentido e alcance; e que, nos contratos de adesão, os escritos devem ser redigidos em termos claros, legíveis e ostensivos, de modo a facilitar a compreensão pelo consumidor, bem como que as cláusulas que impliquem limitação de direito do consumidor devem ser destacadas, a fim de permitir a imediata e fácil compreensão pelo consumidor.

Para Marques, o direito básico do consumidor à informação representa “[...]mais do que um simples elemento formal, afeta a essência do negócio, pois a informação repassada ou requerida integra o conteúdo do contrato (arts. 30, 33, 35, 46 e 54), ou, se falha, representa a falha (vício) na qualidade do produto ou serviço oferecido (arts. 18, 20 e 35) [...]” (MARQUES, BENJAMIM, BESSA, p. 77).

Rev. de Direito, Globalização e Responsabilidade nas Relações de Consumo| e-ISSN: 2526-0030| Goiânia| v. 5 | n. 1 | 
O direito à informação tem relação direta com a liberdade de escolha (art. $6^{\circ}$, inciso II, do Código de Defesa do Consumidor). Isso porque o direito à informação tem como objetivo "[...] preparar o consumidor para um ato de consumo verdadeiramente consentido, livre, porque fundamentado em informações adequadas [...]” (MARQUES, BENJAMIM, BESSA, p. 263), de modo a possibilitar que as suas legítimas expectativas com relação ao produto ou serviço sejam atingidas.

Com relação à conexão entre direito à informação, liberdade de escolha e legítimas expectativas do consumidor, é imperioso apresentar os ensinamentos de Roberto Senise Lisboa (2012, p. 161) com relação à confiança contratual, no sentido de que "[...] o direito às expectativas de esclarecimento consubstanciam a obtenção do conhecimento considerado relevante e adequado em determinado negócio jurídico [...]”, abrangendo a responsabilidade por informações, advertências e conselhos, de modo a “ [...] permitir o nível ideal de conhecimento, para que o confiante possa compreender que o declarante está cooperando a fim de que seu interesse seja objetivo [...]” (SENISE LISBOA, 2012, p. 164).

“A confiança se estabelece a partir de um conhecimento mínimo de informações que proporcione a iniciativa do confiante de aceitar a oferta, publicidade ou proposta, conforme o regime jurídico aplicável” (SENISE LISBOA, 2012, p. 164).

A informação ostensiva, clara e adequada é, portanto, um dos principais princípios e direitos a serem observados nas relações de consumo pois que, com ela, o consumidor tem resguardada a sua liberdade de escolha e o atendimento das suas legítimas expectativas e, por outro lado, sem ela, corre-se o risco de o consumidor ser conduzido ao consumismo e à cultura de massa (EFING, GONÇALVES, 2017), bem como de ser alienado e prejudicado por fornecedores de produtos e serviços que deliberadamente descumprem as normas de defesa do consumidor com o objetivo aumentar as suas vendas e lucros.

\section{3 - A MITIGAÇÃO DO DIREITO À INFORMAÇÃO E DO DEVER DE INFORMAR NA SOCIEDADE DA INFORMAÇÃO}

\section{1 - DADOS SOBRE A EXCLUSÃO DIGITAL NO BRASIL}

Para expor o panorama atual do uso da internet pela população brasileira, utilizamonos de informações e indicadores da pesquisa realizada pelo Centro de Estudos sobre as 
Tecnologias da Informação e Comunicação - CETIC, no ano de 2017 (última pesquisa realizada), publicada no dia 24 de julho de 2018, que teve "como objetivo principal medir a posse e o uso das tecnologias de informação e de comunicação entre a população residente no Brasil com idade de 10 anos ou mais" (CETIC, 2018).

Apresentaremos informações relativas aos seguintes seguimentos de pesquisa: domicílios com acesso à internet, segmentando pelo total no Brasil, por região e por classe social; domicílio com acesso à internet e presença de computador, segmentando pelo total no Brasil, por região e por classe social; domicílio sem acesso à internet, por motivos para a falta de internet, segmentado pelo total no Brasil, por região e por classe social.

De acordo com a pesquisa realizada pelo CETIC, 46\% dos domicílios no Brasil não possuem acesso à internetż. Tomando por base a segmentação por região, observou-se que o percentual de domicílios que não possuem acesso à internet na região Norte é de 54\%; na região Nordeste é 59\%; na região Sudeste é de 36\%; na região Sul é de 47\%; e na região Centro-Oeste é de $44 \%$ ?3. Já na segmentação por classe social, constatou-se que o percentual de domicílios que não possuem acesso à internet é de apenas $2 \%$ na classe $\mathrm{A}$; $9 \%$ na classe $\mathrm{B} ; 39 \%$ na classe $\mathrm{C}$; e 76\% nas classes D e E (CETIC, 2018).

Com relação aos domicílios com acesso à internet e presença de computador, a pesquisa realizada pelo CETIC constatou a alarmante realidade de que apenas $41 \%$ dos domicílios no Brasil possuem acesso à internet e computadors. Considerando-se as informações obtidas por região, observou-se que o percentual de domicílios que possuem acesso à internet e computador na região Norte é de 22\%; na região Nordeste é 28\%; na região Sudeste é de 51\%; na região Sul é de 44\%; e na região Centro-Oeste é de 48\% (CETIC, 2018). Já na segmentação por classe social, constatou-se que o percentual de domicílios possuem acesso à internet e computador é de $98 \%$ na classe A; $88 \%$ na classe B; $45 \%$ na classe C; e $7 \%$ nas classes D e E (CETIC, 2018).

Com relação aos domicílios sem acesso à internet segmentado por motivação, a pesquisa do CETIC concluiu que $42 \%$ do total dos domicílios brasileiros não possuem acesso à internet em razão de os moradores não saberem utilizá-la e $28 \%$ em razão da falta de disponibilidade na região (CETIC, 2018). Levando-se em consideração as informações da pesquisa segmentada por região, observa-se que o percentual de domicílios que não possuem acesso à internet em razão de os moradores não saberem utilizá-la e em razão da falta de disponibilidade são, respectivamente, os seguintes: região Norte, $39 \%$ e 46\%, região Nordeste, 
$41 \%$ e $28 \%$; região Sudeste, $43 \%$ e $26 \%$; região Sul, $40 \%$ e 24\%; e região Centro-Oeste, $44 \%$ e 27\% (CETIC, 2018).

Na segmentação por classe social constatou-se que o percentual de domicílios que não possuem acesso à internet em razão de os moradores não saberem utilizá-la e em razão da falta de disponibilidade são, respectivamente, os seguintes: na classe A não constou indicadores; na classe B, 22\% e 23\%; na classe C, 34\% e 22\%; e nas classes D e E, 47\% e 32\% (CETIC, 2018).

Considerando-se as informações apresentadas, constata-se que, muito embora o Brasil tenha evoluído na disseminação do acesso e uso da internet ao longo dos últimos anos, grande parte da população ainda não tem acesso a ela.

A disparidade socioeconômica, conforme observado, é um dos fatores mais relevantes para a exclusão e falta de educação digital da população. Não restam dúvidas, portanto, de que no atual cenário nacional a exclusão digital está diretamente ligadas às desigualdades sociais e regionais.

\section{2 - A MITIGAÇÃO DO DEVER DE INFORMAR PELA INTERPRETAÇÃO RESTRITIVA DAS RELAÇÕES DE CONSUMO NA SOCIEDADE DA INFORMAÇÃO}

Conforme apresentado no capítulo anterior, o direito à informação tem como objetivo "[...] preparar o consumidor para um ato de consumo verdadeiramente consentido, livre, porque fundamentado em informações adequadas [...]" (MARQUES, BENJAMIM, BESSA, 2014, p. 263), de modo a possibilitar a sua liberdade de escolha consciente e que as suas legítimas expectativas com relação ao produto ou serviço sejam devidamente atingidas, não podendo o fornecedor se furtar de cumprir com o seu dever de informar. Não resta dúvida, portanto, que a informação ostensiva, clara e adequada sobre os produtos e serviços colocados no mercado de consumo é inerente à relação de consumo e um dos principais mecanismos de proteção do consumidor.

Ocorre que, com o advento da sociedade informação e a consequente modernização e digitalização dos meios de informação e comunicação, relações jurídicas - relações de consumo, por exemplo - foram criadas ou modificadas, adaptando-se ao universo digital, passando a ter etapas digitais e, até mesmo, a serem firmadas de forma totalmente digital, sem a presença física dos contratantes (consumidor e fornecedor, no caso), tal como se observa nas compras realizadas por meio de lojas on-line, contratações de serviços que são realizadas exclusivamente por meio eletrônico, entre outras, o que acaba, por vezes, tornando deficitária as informações transmitidas ao consumidor. 


\title{
A HERMENÊUTICA JURÍDICA COMO CAMINHO PARA O REEQUILÍBRIO DA PROTEÇÃO DO DIREITO À INFORMAÇÃO NAS RELAÇÕES DE CONSUMO NA SOCIEDADE DA INFORMAÇÃO.
}

Como forma de ilustrar esse novo cenário de relações jurídicas total ou parcialmente digitais e a mitigação do direito/dever de informação nas relações de consumo na sociedade da informação, apresentaremos, em linhas gerais, um caso concreto de relação de consumo (contrato de seguro) julgado pelo Tribunal de Justiça do Estado de São Paulo ${ }^{1}$, no qual observou-se a expressa mitigação do dever de informar por parte dos julgadores.

O caso analisado e julgado pelo Tribunal de Justiça do Estado de São Paulo versava, dentre outros fundamentos, sobre o dever de indenizar por parte da seguradora em razão de ela, supostamente, não ter prestado informações expressas, claras e precisas sobre os crimes que seriam cobertos pela apólice de seguro de automóvel. A autora da ação argumentou que a seguradora não prestou os esclarecimentos devidos no momento da contratação, razão pela qual restaria configurada a violação do direito à informação e do dever de informar, ensejando, consequentemente, o dever de indenizar. A seguradora, de seu lado, apresentou defesa argumentando ter cumprindo com o direito à informação e o dever de informar, porquanto disponibiliza em seu website cópia completa das condições contratuais das apólices comercializadas, de modo a dar publicidade e permitir que os consumidores tomem conhecimento do conteúdo previamente à contratação.

Julgado o caso, os juízos de primeiro e de segundo grau entenderam não ter havido violação do dever de informar, apresentando o seguinte fundamento:

\begin{abstract}
Como bem destacado pelo Juízo da causa, não diviso, de início, violação ao dever de informar previsto no Código de Defesa do Consumidor, porquanto a ré, assim como outras seguradoras, mantém disponíveis em seu endereço eletrônico as condições contratuais de todas as apólices comercializadas, exatamente para dar oportunidade de os segurados conhecerem, previamente à contratação, os limites e as exclusões das garantias oferecidas.
\end{abstract}

Ao aceitarem a tese da seguradora, no sentido de que a conduta de disponibilizar o inteiro teor do contrato no seu website, sem dar prévio conhecimento dos seus termos ao consumidor no momento da contratação, está em consonância com os ditames consumeristas com relação ao direito à informação e ao dever de informar, denota que os julgadores do Tribunal de Justiça do Estado de São Paulo desconhecem a realidade brasileira com relação ao acesso da população às tecnologias da informação e comunicação (TICs), bem como que exercem uma atividade interpretativa extremamente restritiva, haja vista que não se preocuparam analisar as circunstâncias externas à norma jurídica positivada

$1 \mathrm{O}$ caso concreto pode ser conferido e analisado pelo leitor por meio do seguinte link: https://esaj.tjsp.jus.br/cpopg/show.do?processo.codigo=2S000CMLM0000\&processo.foro=100\&uuidCaptcha=s ajcaptcha_e7abc8ceb2e64417ace43040903f5d12 
Conforme apresentado no tópico antecedente, muito embora vivamos na sociedade da informação, e as tecnologias da informação e comunicação (TICs) tenham evoluído sobremaneira nas últimas décadas, o Brasil ainda é um país onde expressiva parcela da população é excluída digitalmente. A pesquisa realizada pelo CETIC no ano de 2017, conforme apresentado, revelou que $46 \%$ dos domicílios brasileiros não possuem acesso à internet, sendo que parte expressiva dessa totalidade é concentrada na área rural e nas Classes socais D e E.

O posicionamento interpretativo dos magistrados do Tribunal de Justiça do Estado de São Paulo confirma a afirmação de Castells (2003, p. 203) no sentido de que "[...] a centralidade da internet em muitas áreas da atividade social, econômica e política equivale a marginalidade para aqueles que não têm acesso a ela ou têm apenas um acesso limitado, bem como para os que são incapazes de usá-la eficazmente [...]”. Isso porque, ao decidirem no sentido de que basta o fornecedor disponibilizar as condições gerais do contrato em seu website para restar cumprido o dever de informar, os magistrados colocam à margem da sociedade aqueles que não têm acesso e/ou educação para o uso deste tipo de tecnologia da informação e comunicação, Seguindo a lógica de raciocínio dos magistrados, somente aqueles que têm acesso e educação para o uso das TICs é que poderão adquirir produtos e contratar adequadamente determinados serviços. Se não o tiverem, ficarão sujeitos aos arbítrios das grandes corporações.

Em vista disso, pode-se falar numa sociedade da informação "[...] caracterizada pela diluição de barreiras e excesso de informações, mas que não permite a seus membros assimilar essas informações e sequer possuir o discernimento necessário para escolher livremente na sociedade de consumo [...]" (EFING, GONÇALVES, BALBI, 2017. P. 72).

Considerando-se a sociedade informacional e tecnológica na qual vivemos, a análise das relações de consumo criadas e modificadas não pode ser desprovida de percepção da realidade brasileira com relação à disponibilidade e ao uso de tecnologias da informação e comunicação por parte da população, sob pena de tornar o consumidor ainda mais vulnerável no mercado de consumo, e de favorecer ainda mais as grandes corporações que, cada vez mais, visam ao lucro em detrimento dos consumidores, bem como de acrescentar “[...] uma divisão essencial às fontes já existentes de desigualdade e exclusão social, numa interação complexa que parece aumentar a disparidade entre a promessa da Era da Informação e sua sombria realidade para muitos em todo o mundo [...]" (CASTELLS, 2003, p. 203). 


\section{4 - A HERMENÊUTICA JURÍDICA COMO CAMINHO PARA O REEQUILÍBRIO DO} DIREITO À INFORMAÇÃO NAS RELAÇÕES DE CONSUMO NA SOCIEDADE DA INFORMAÇÃO

Conforme apresentado, inclusive por meio da breve análise de um caso concreto julgado pelo Tribunal de Justiça do Estado de São Paulo, é possível observar que as modificações sociais decorrentes da evolução tecnológica já surtem efeitos significativos nas relações jurídicas.

Levando-se em consideração que sociedade brasileira (e mundial), em razão da rápida e crescente evolução tecnológica, vem passando por grandes modificações, cujos reflexos pode ser observados direta e indiretamente nas relações jurídicas, sociais e culturais, e que não há a proporcional transformação e evolução do ordenamento jurídico, gerando, assim, conflitos e questionamentos no âmbito da atividade jurídica acerca de como o direito deve ser interpretado e aplicado às relações jurídicas modificadas e criadas, torna-se ainda mais imperiosa busca por novas maneiras de interpretar o direito, de modo a se reestabelecer o equilíbrio nas relações jurídicas, especialmente naquelas em que há uma parte presumidamente vulnerável, tal como se observa nas relações de consumo.

Dado o caráter aberto de sua hermenêutica jurídica, que traz uma visão mais ampla do universo normativo ao estabelecer que ele é plural, que é constituído não somente pelas normas positivadas, mas também por uma pluralidade de nomos, devendo a hermenêutica jurídica compreender, além do corpo jurídico estatal, a pluralidade das narrações histórico-culturais existentes na sociedade, não tratando a hermenêutica como mera atividade reprodutiva e restritiva, mas sim como de criação 
do significado jurídico de acordo com as narrativas que constituem a identidade da sociedade, é que, neste capítulo, ter-se-á como referencial teórico a teoria hermenêutica de Robert Cover, a seguir brevemente analisada.

\section{1 - A PLURALIDADE DO UNIVERSO NORMATIVO}

De acordo com Robert Cover, nós habitamos um nomos, ou seja, um universo normativo, que não é unicamente constituído pelo universo normativo positivado nas leis. O universo normativo é composto, também, pelas narrações históricas que constituem a identidade cultural de cada grupo social. Para ele o mundo do nomos é

[...] tão real como o universo físico de massa, força e energia. Mais ainda, nossa
apreensão da estrutura do mundo normativo é tão fundamental como nossa percepção
da estrutura do mundo físico. Do mesmo modo em que com o nascimento começa o
desenvolvimento de respostas crescentemente complexas diante dos atributos físicos
do mundo, também se inicia o desenvolvimento paralelo de respostas à existência de
outras pessoas que define o mundo normativo (COVER, 2002, p. 17, tradução nossa).

"Um nomos, como um mundo do direito, envolve a aplicação da vontade humana tanto a um estado de coisas existente como às nossas visões alternativas do futuro. Um nomos é um mundo presente constituído por um sistema de tensão entre realidade e visão (COVER, 2002, p. 23, tradução nossa).

Uma grande civilização jurídica, segundo Cover (2002, p. 18, tradução nossa), é caracterizada pela riqueza do nomos no qual se situa e que contribuiu para construir. $\mathrm{O}$ diversificado e complexo “[...] material desse estabelece paradigmas de consagração, resignação, contradição e resistência. Este material não apenas apresenta corpos e regras ou doutrinas que exigem interpretação, mas mundos para habitar. Habitar um nomos é saber como viver nele".

As instituições formais do direito, as regras e princípios e as convenções de ordem social são, segundo Cover, importantes, entretanto, não devem ser consideradas como as únicas pertencentes ao universo normativo. São, em realidade, uma pequena parcela deste universo que devemos observar ${ }^{2}$.

2 "El estudiante de derecho puede llegar a identificar el mundo normativo con la parafernalia professional de control social. Las reglas y principios de justicia, las instituiciones formales del derecho y las convenciones del orden social son, por supuesto, importantes para esse mundo; y sin embargo, sólo son una pequeña parte del universo normativo que deveria llmar nuestra atención". (COVER, 2002, p. 16) 
As normas positivadas são, portanto, parte constitutiva de um complexo mundo normativo, no qual não há somente o corpo jurídico Estatal, “[...] mas também uma linguagem e um mito - narrações em que colocam o corpis juris que expressam sua vontade por meio dela [...] (COVER, 2002, p. 22, tradução nossa)". Trata-se de posição contrária ao pensamento positivista que enxerga o universo normativo como um corpo jurídico composto apenas pelas normas postas pelo Estado, deixando de lado as narrações históricas (a tradição, os costumes e o direito não escrito) presentes na sociedade.

Retornando aos gregos, Cover (2002, p. 30, tradução nossa) considera que todo nomos deve ser paidético, "na medida em que contém dentro de sí o caráter comum de significado que faz possível a atividade normativa contínua" devendo a lei ser significativa no sentido de permitir que aqueles que vivem juntos possam se expressar através dela e com respeito a ela, oferecendo, ao mesmo tempo, elementos para um comportamento previsível, dando, inclusive, significado ao comportamento diverso do que se considera comum.

Viver num mundo jurídico, portanto, para Cover (2002), exige que conheçamos as suas conexões com o estado de coisas possível e plausível, e não somente os preceitos legais, não só o ser e o dever-ser, mas, também, o poder-ser ${ }^{3}$. Em vista disso, deve-se abrir os horizontes do direito, passando a considerá-lo como um fenômeno plural, vivenciado por variados grupamentos humanos, levando-se em consideração as narrações históricas que constituem as circunstâncias e a identidade cultural de cada grupo existente na sociedade, e não "[...] seguir aprisionando-o por meio de narrativas estatalistas, que não raro conduzem à supressão violenta do jus em favor da lex” (SOLON, 2017, 109).

\section{2 - A HERMENÊUTICA JURÍDICA E O REEQUILÍBRIO DA PROTEÇÃO DO DIREITO À INFORMAÇÃO NAS RELAÇÕES DE CONSUMO NA SOCIEDADE DA INFORMAÇÃO}

Conforme observado no tópico antecedente, Cover (2002) considera que o universo normativo não deve ser simples e unicamente identificado às instituições formais do direito, às regras e princípios e/ou às convenções de ordem social. Deve-se ir além disso. Isso porque o

3"La narrativa integra estos dominios. Las narraciones son modelos a través de los cuales estudiamos y experimentamos las transformaciones que ocurren cuando se hace pasar un cierto estado de cosas simplificado a través del campo de fuerza de un conjunto de normas igualmente simplificado" (COVER, 2002, p. 24). 


\section{A HERMENÊUTICA JURÍDICA COMO CAMINHO PARA O REEQUILÍBRIO DA PROTEÇÃO DO DIREITO À INFORMAÇÃO NAS RELAÇÕES \\ DE CONSUMO NA SOCIEDADE DA INFORMAÇÃO.}

universo normativo é plural, no qual diferentes grupamentos humanos buscam reconhecimento de suas narrativas perante o sistema jurídico estatal.

No que toca à hermenêutica jurídica, Cover (2002) critica a posição daqueles que consideram que só o Estado cria o direito - tal como a concepção juspositivista estrita de Hans Kelsen ${ }^{4}$-, argumentando que essa posição confunde a interpretação do direito com a dominação política estatal. Isso porque, segundo ele, a lei estatal, ao exercer a sua força, exclui a possibilidade de uma hermenêutica criadora de princípios conforme o nomos disseminado em diferentes comunidades. Considerando que o nomos “[...] é mais do que um processo de ação humana esticado entre visão e realidade, uma interpretação legal não pode ser válida se não estiver preparada para viver de acordo com ela [...] (COVER, 2002, p. 75, tradução nossa).

De acordo com Cover (2002), o conjunto de instituições jurídicas e de preceitos legais não existem sem um contexto narrativo que lhes deem significado. Ainda segundo o autor, toda constituição possui uma épica, e "[...] quando é entendido no contexto das narrações que lhe dão significado, o direito deixa de ser um mero sistema de regras a observar, e se transforma em um mundo em que vivemos [...] (COVER, 2002, p. 16). Direito e narração, no mundo normativo, estão ligados umbilicalmente, razão pela qual toda norma legal deve ser situada dentro de um discurso com começo e fim, com uma explicação e um propósito.

O problema da hermenêutica jurídica se revela, portanto, “[...]como um problema filosófico mais amplo, não se limitando à questão da "incidência" de uma norma a um caso [...]" (SOLON, 2017, p. 106). Trata-se de um problema voltado à criação de significado jurídico, de atribuição de sentido, levando-se em conta os diversos aspectos que cercam a situação concreta.

A criação de um significado jurídico exige um compromisso de compreensão do direito por meio da identificação dos nomos apresentados no caso concreto, por meio da identificação de todos os mundos possíveis. Exige-se uma narração ${ }^{5}$. O alcance do significado jurídico se define “[...] tanto por um texto legal que objetiva a demanda, como por uma multiplicidade de compromissos implícitos e explícitos que a acompanham” (COVER, 2002, p. 75).

\footnotetext{
4 "Para Kelsen, o direito pertence ao mundo do dever-ser; logo, não se há de pensar, juridicamente, com base no que é ou acontece no mundo dos fatos, pois o dever-ser não deriva do ser nem vice-versa" (COMPARATO, 2016, p. 361).

5 "Un sentido prescriptivo, un mensaje moral. La historia y la literartura tampoco pueden evitar ser situadas en un universo normativo, y ni siquiera las prescripciones, aun cuando estén incorporadas a un texto legal, pueden escapar de su origen y su fin en la experiencia, en las narraciones que constituen las trayectorias tramadas a partir de la realidad material por nuestra imaginación" (COVER, 2002, p. 16).
} 


\section{A HERMENÊUTICA JURÍDICA COMO CAMINHO PARA O REEQUILÍBRIO DA PROTEÇÃO DO DIREITO À INFORMAÇÃO NAS RELAÇÕES \\ DE CONSUMO NA SOCIEDADE DA INFORMAÇÃO.}

O pensamento de Cover, inclusive por apresentar algumas posições, ainda que, por vezes, de forma crítica $^{6}$, dialoga com o pensamento de Martin Heidegger e Hans-Georg Gadamer, na medida em que eles propõe “ [...] que a interpretação não é uma leitura direta e indiferente de normas e fatos, mas sim uma compreensão existencial [...]” (MASCARO, 2015, p. 167), ou seja, “[...] uma tomada de entendimento a partir de uma determinada situação construída socialmente [...] (MASCARO, 2015, p. 167)”.

Solon (2017, p. 106), em posicionamento que se coaduna com a teoria de Cover, dispõe que a hermenêutica não deve ser considerada simplesmente como "[...] método para 'aplicação de normas jurídicas', mas como modo de constituição do direito, que deve ser hermeneuticamente concebido como em constante e dinâmica atualização [...]”, de modo a permitir o acolhimento nomos jurídicos insurgentes, transcendendo, assim, o problema da hermenêutica como simples subsunção de normas jurídicas a casos concretos, a fim de alcançar a superação da lex pelo jus.

A hermenêutica jurídica, considerando as teorias de Robert Cover e Ari Marcelo Solon, não deve consistir, portanto, num simples método de aplicação de normas jurídicas a casos concretos, numa mera reprodução de um direito preexistente, mas sim numa atividade criadora de significado jurídico por intermédio da narrativa do nomos apresentado, identificando-se a historicidade que constitui a identidade de cada grupamento humano e do caso concreto apresentado, possibilitando, assim, que as relações e os eventuais conflitos modificados e criados em decorrência dos avanços tecnológicos na sociedade da informação, ao não encontrarem solução clara, específica e objetiva no ordenamento jurídico para a solução de controvérsia - já que a criação normativa não consegue acompanhar o

6 Cover (2002) critica, em parte, o pensamento de Gadamer. Isso porque, considera-o como completamente estatista, motivo pelo qual, consequentemente, não se preocupa com a questão dos problemas hermenêuticos peculiares a todos os sistemas normativos objetivados (estatais ou não estatais), e, também, aborda inadequadamente a questão da destruição da hermenêutica nas mãos da oficialidade. 
rápido e irrefreado avanço da tecnologia -, possam encontrar solução e amparo compatíveis com as circunstâncias apresentadas.

A percepção do direito como significado, “[...] como atualização hermenêutica constante, superando o datado modo de percepção do fenômeno jurídico como exercício legítimo da violência pelo poder estatal [...] (SOLON, 2017, p. 109)" representa, além do acolhimento da narrativa mais adequada à vivência jurídica, a percepção de que o direito é vivenciado por diferentes grupamentos humanos. Em vista disso, o operador do direito, especialmente o magistrado, no momento de analisar e interpretar determinado conflito observado na relação de consumo com relação ao efetivo cumprimento ou não do direito à informação e do dever de informar frente às novas circunstâncias tecnológicas e digitais, deve levar em consideração a narrativa, o nomos daqueles desprovidos, com acesso limitado ou que não têm educação para o uso TICs, de modo a reestabelecer o equilíbrio da proteção do direito à informação nas relações de consumo, e de não tornar os consumidores ainda mais vulneráveis e sujeitos ao arbítrio das grandes corporações no mercado de consumo.

\section{CONCLUSÃO}

A informação ostensiva, clara e adequada é um dos principais princípios e direitos consagrados no Código de Defesa do Consumidor, e que deve ser impreterivelmente observada nas relações de consumo, de modo a resguardar a liberdade de escolha e o atendimento das suas legítimas expectativas do consumidor, bem como de protegê-lo de fornecedores de produtos e serviços que deliberadamente descumprem as normas de defesa do consumidor com o objetivo aumentar as suas vendas e lucros.

Com o advento da sociedade informação e a consequente modernização e digitalização dos meios de informação e comunicação, relações jurídicas - relações de consumo, por exemplo - adaptaram-se ao universo digital, passando a ter etapas digitais e, até mesmo, a serem firmadas de forma totalmente digital, sem a presença física dos contratantes (consumidor e fornecedor, no caso), acabando por tornar, por vezes, deficitária as informações transmitidas ao consumidor, bem como conflituosa a questão interpretativa acerca do cumprimento ou não do direito à informação e do dever de informar em determinadas situações. 


\section{A HERMENÊUTICA JURÍDICA COMO CAMINHO PARA O REEQUILÍBRIO DA PROTEÇÃO DO DIREITO À INFORMAÇÃO NAS RELAÇÕES \\ DE CONSUMO NA SOCIEDADE DA INFORMAÇÃO.}

Observou-se, no decorrer deste artigo, que muito embora vivamos na sociedade da informação, o Brasil ainda é um país onde expressiva parcela da população é excluída digitalmente. A pesquisa realizada pelo CETIC no ano de 2017 , apontou que $46 \%$ dos domicílios brasileiros não possuem acesso à internet, sendo que parte expressiva dessa totalidade é concentrada na área rural e nas Classes socais D e E. Tais circunstâncias são de extremo relevo no momento de se analisar as relações jurídicas criadas e/ou modificadas pelo implemento das tecnologias da informação e comunicação, especialmente naquelas em que uma das partes é presumidamente vulnerável, tal como ocorre nas relações de consumo.

Considerando-se a sociedade informacional e tecnológica na qual vivemos, a análise das relações de consumo criadas e modificadas não pode ser desprovida de percepção da realidade brasileira com relação à disponibilidade e ao uso de tecnologias da informação e comunicação por parte da população, especialmente no que diz respeito ao direito à informação e o dever de informar, sob pena de tornar o consumidor ainda mais vulnerável no mercado de consumo, e de favorecer ainda mais as grandes corporações que, cada vez mais, visam ao lucro em detrimento dos consumidores. Em vista disso, o operador do direito, especialmente o magistrado, deve levar em consideração a narrativa, o nomos daqueles desprovidos, com acesso limitado ou que não têm educação para o uso TICs, de modo a reestabelecer o equilíbrio da proteção do direito à informação nas relações de consumo na sociedade da informação.

\section{REFERÊNCIAS BIBLIOGRÁFICAS}

BITTAR, Eduardo C. B.; ALMEIDA, Guilherme Assis de. Curso de Filosofia do Direito. $7^{\text {a }}$ ed. São Paulo: Atlas, 2009.

BOBBIO, Noberto. O Positivismo Jurídico: Lições de filosofia do direito. São Paulo: Ícone, 2006.

CASTELLS, Manuel. A galáxia da internet: reflexões sobre a internet, os negócios e a sociedade. Rio de Janeiro: Zahar, 2003.

CASTELLS, Manuel. Redes de indignação e esperança: movimentos sociais na era da internet. Trad. Carlos Alberto Medeiros. 2a ed. rev. E atual. Rio de Janeiro: Zahar, 2017.

COMITÊ GESTOR DA INTERNET NO BRASIL. Pesquisa sobre o uso das tecnologias de informação e comunicação nos domicílios brasileiros - TIC Domicílios 2016. Disponível em: http://data.cetic.br/cetic/explore?idPesquisa=TIC DOM. Acessado em 17 de outubro de 2018. 


\section{A HERMENÊUTICA JURÍDICA COMO CAMINHO PARA O REEQUILÍBRIO DA PROTEÇÃO DO DIREITO À INFORMAÇÃO NAS RELAÇÕES \\ DE CONSUMO NA SOCIEDADE DA INFORMAÇÃO.}

COMPARATO, Fábio Konder. Ética: direito, moral e religião no mundo moderno. $3^{\text {a }}$ ed. São Paulo: Companhia das Letras, 2016.

COVER, Robert. Derecho, narración y violencia. $1^{\text {a }}$ ed. Barcelona: Editorial Gedisa, 2002. Sampaio. A ciência do direito. $2^{\mathrm{a}}$ ed. São Paulo: Atlas: 2010.

EFING, Antônio Carlos; GONÇALVES, Bruna Balbi. O direito fundamental à informação na sociedade de consumo e a rotulagem de transgênicos: Uma análise do Projeio de Lei n. 4.148/2008. Revista do Programa de Pós-Graduação em Direito da UFC. v. 37.2, jul./dez. 2017 , p. $69 / 86$.

LISBOA, Roberto Senise. Confiança Contratual. São Paulo: Atlas, 2012.

LISBOA, Roberto Senise. Direito na sociedade da informação. Revista dos Tribunais. São Paulo, v. 95, n. 847, p. 78-98, mai/2006.

LISBOA, Roberto Senise. Proteção do consumidor na sociedade da informação. Revista de Direito Privado da Universidade Estadual de Londrina. Vol.2, n 1, jan/abr 2009.

MARQUES, Claudia Lima; BENJAMIN, Antonio Herman V.; BESSA, Leonardo Roscoe. Manual de Direito do Consumidor. $6^{a}$ ed. São Paulo: Revista dos Tribunais, 2014, p. 77.

MASCARO, Alysson Leandro. Filosofia do Direito. 4ª ed. São Paulo: Atlas, 2014.

MASCARO, Alysson Leandro. Introdução ao Estudo do Direito. $5^{\text {a }}$ ed. São Paulo: Atlas, 2015.

PAESANI, Liliana Minardi. O direito na Sociedade da Informação. São Paulo: Atlas, 2007.

PAESANI, Liliana Minardi. O direito na Sociedade da Informação II. São Paulo: Atlas, 2009.

MORRISON, Wayne. Filosofia do direito - Dos gregos ao pós-modernismo. $2^{\mathrm{a}}$ ed. São Paulo: Editora WMF Martins Fontes, 2012.

SIMÃO FILHO, Adalberto; BARRETO JR, Irineu Francisco; LISBOA, Roberto Senise; ANDRADE, Ronaldo Alves de. Direito da Sociedade da Informação: Temas Jurídicos Relevantes. São Paulo: Quartier Latin, 2012.

SOLON, Ari Marcelo. Hermenêutica jurídica radical. $1^{\text {a }}$ ed. São Paulo: Marcial Pons, 2017. 